\title{
Ureteral Wall Thickness is an Independent Parameter Affecting the Success of Extracorporeal Shock Wave Lithotripsy Treatment in Ureteral Stones above the Iliac Crest
}

\author{
Emre Bulbul ${ }^{1}$, Fahri Yavuz Ilki ${ }^{1}$, Mehmet Hamza Gultekin ${ }^{2}$, Ahmet Erozenci ${ }^{1}$, Onur \\ Tutar $^{1}$, Sinharib Citgez ${ }^{1}$, Nejat Tansu ${ }^{1}$, and Bulent Onal ${ }^{3}$ \\ ${ }^{1}$ Istanbul University-Cerrahpasa Cerrahpasa Faculty of Medicine \\ ${ }^{2}$ Haseki Education Research Hospital \\ ${ }^{3}$ Istanbul Universitesi-Cerrahpasa
}

December 1, 2020

\begin{abstract}
Background: To investigate the relationship between ureteral wall thickness (UWT) and other variables of patients who underwent extracorporeal shock wave lithotripsy (SWL) in the primary treatment of the ureteral stone above the iliac crest level. Material and methods: A total of 147 patients aged 18 years and older, who underwent SWL in our clinic between December 2016 and December 2019 for the treatment of ureteral stones above the iliac crest level and had a non-contrast-enhanced abdominal computed tomography (NCCT) scans before the procedure were included in the clinical study. The results were evaluated at three months after SWL. The absence of residual fragments was considered as stone-free status, and the existence of any size residual fragment was considered as treatment failure. Results: In our study, the mean age of the patients was 42.4 \pm 12.8 years, and the stone-free rate was $92.5 \%$. The median transverse stone size was $7.5 \mathrm{~mm}(\min 2.8-\max 15)$, and the median UWT was $4.2 \mathrm{~mm}(1-8.7)$. In the multivariate analysis, UWT $(\mathrm{p}=0.002)$ and multiple stone presence $(\mathrm{p}=0.027)$ were found to be independent factors affecting stone-free status. In the receiver operating characteristic (ROC) curve analysis, the optimal threshold value for UWT was determined as $5.25 \mathrm{~mm}$. Conclusions: We found that UWT was the most important independent variable associated with increased failure in SWL treatment. The presence of multiple stones was another independent factor that increased failure rates. Using SWL technology through experience accumulated with the mechanical hardware of the machine, we can select patients who are more suitable for this treatment and improve treatment outcomes.
\end{abstract}

\section{Introduction}

The European Association Urology (EAU) guidelines recommend extracorporeal shock wave lithotripsy (SWL) or ureterorenoscopy (URS) as the first choice of treatment in proximal ureteral stones of less than $10 \mathrm{~mm}$ while for those larger than $10 \mathrm{~mm}$, the first option is URS and the second option is SWL treatment. [1] SWL is the most minimally invasive and anesthesia-free option in stone treatment. Most patients can be treated in outpatient settings. Many factors affect the results of SWL treatment. Proper patient selection increases the success rate, and stone size is inversely proportional to treatment success. [2] In addition, it has been stated that the ability of stone targeting affects the success rate. [3]

In the disease process, if the impacted stones remain in the same location for a long time, the contact of the stone with the ureteral mucosa can cause local inflammation and edema [4,5], leading to an increase in the ureteral wall thickness (UWT). In a previous study, SWL success was reported to decrease as the UWT increased in patients with impacted proximal ureter stones. In that study, an impacted stone was defined as a ureteral stone remaining in the same position (and/or presence of symptoms) for at least one month, 
accompanied by the failure of visualization of the distal segment of the ureter beneath the segment of the stone on intravenous urography or computed tomography (CT) urography. [6] However, there is insufficient data in the literature regarding the definition of impacted ureteral stones. Most definitions provided are subjective and aim to improve the success of SWL treatment. When the literature studies are analyzed, a discrepancy is also observed in relation to the predictive factors affecting success in the SWL treatment of proximal ureteral stones. $[7,8]$ Therefore, it is still difficult to choose the appropriate treatment for proximal ureteral stones.

Innovations in SWL technology have increased the success rate and made it a favorable choice of treatment. In this study, we aimed to determine the predictors that might affect the stone-free status. For this purpose, we investigated the effect of UWT and other variables on the treatment results in patients who received SWL as the primary treatment of ureteral stones above the iliac crest level.

\section{Materials and Methods}

The study included patients aged 18 years or older, who received SWL treatment for ureteral stones above the iliac crest-level between December 2016 and December 2019 at the Urology Department of a University Hospital. This study was approved by the Institutional Review Board on November 21, 2018 (number: 21263603-806.01.03-96286). SWL is the primary treatment option in our clinic as it is the most minimally invasive option. It was applied to all ureteral stones above the iliac crest, regardless of patient selection. The patients who underwent SWL as the primary treatment option between the specified dates were analyzed retrospectively. Patients with congenital abnormalities, coagulopathy, morbid obesity, pain intolerance, stone size more than $15 \mathrm{~mm}$, secondary treatment or renal failure were excluded from the study (URS was performed to these patients). A total of 147 patients with ureteral stones above the iliac crest-level, who underwent non-contrast enhanced abdominal computed tomography (NCCT) before the SWL procedure and when they had ureteral stone which were not passed in four weeks, were included in the clinical study.

A urine culture-antibiogram test was applied to the patients before the procedure. In cases where the urine culture was not sterile, the patients were given an appropriate antibiotic treatment, and SWL treatment was applied after confirming sterile urine culture with the approval of an infectious diseases specialist. SWL was performed by a single urologist (NT) with 30 years of SWL experience using a third-generation lithotripter (Siemens Lithoscope ${ }^{\circledR}$, Erlangen, Germany). The procedure was undertaken in the outpatient setting under fluoroscopic control without administering anesthesia. Analgesic and spasmolytic treatment was applied to the patients during the procedures. The patients were placed in the supine position. Treatment was started with an energy level of 60 joules and gradually increased until it reached a maximum value of 120 joules if tolerated by patients. Initially, the shock wave/minute ratio was set to 60 for the first 500 shock waves, and then increased to 90 shock waves/minutes. Although 3000 shock waves were applied in each session, when the clinician deemed it necessary, the number of shock waves was increased to a maximum of 3800 . Treatment was terminated when complete fragmentation of the stone was noted on fluoroscopy. If there was persistent or incomplete fragmentation of the stone(s) noted on fluroscopy after the maximum number of shocks had been delivered, a repeat SWL session was performed at five-seven days after the previous one. When appropriate fragmentation was seen in each session, the procedure was scheduled for next sessions. SWL was regarded as a failure if no fragmentation was noted after the third session. The results were defined as stone-free status and treatment failure according to the NCCT evaluation undertaken at three months after SWL. Stone-free status was defined as the absence of stones while treatment failure was indicated by the presence of any residual stone regardless of size. In addition, at the time of SWL or after the procedure before the third-month CT evaluation, URS was performed in all patients who required an additional intervention due to increased pain or steinstrasse (defined as failure).

The demographic characteristics of the patients (age, gender, comorbidity, and history of stone surgery on the same side) and stone characteristics [side of the stone, diameter of the ureter in the proximal of the stone, transverse stone size, stone length, stone volume, mean Hounsfield unit (HU), hydronephrosis degree, distance between the stone and the skin (SSD), and number of stones were recorded. The NCCT images at $4 \mathrm{X}$ magnification were used. We evaluated the images in three axes (in the axial, sagittal, and coronal 
plane measurements). The largest UWT was obtained from NCCT at the stone site. The ellipsoid formula $(\pi \times$ length $\times$ transverse size $\times$ sagittal size $\times 0.167)$ was used when calculating the stone volume. SSD was calculated by measuring the distance from the skin to the stone in a $45^{\circ}$ posterolateral direction. The characteristics of the SWL treatment applied to the patients (number of sessions, number of shock per session, and amount of energy applied per session) were noted.

The selected cross-section range in NCCT was $1.25 \mathrm{~mm}$. The patients were scanned without a contrast agent using a tube voltage of $120 \mathrm{kV}$ and tube current of $300 \mathrm{mAs}$. Using the NCCT images taken before each SWL session of each stone, all parameters were measured by a single radiologist (OT) with 15 years' experience in abdominal radiology, who was blinded to the treatment results of the patients. NCCT was used for follow-up after SWL. The effect of patient- and stone-related parameters on stone-free status was analyzed.

Statistical analyses were performed using the Statistical Package for the Social Sciences (SPSS) version 22.0. The compliance of data to normal distribution was evaluated by the Shapiro-Wilk test. Normally distributed data were indicated by mean and standard deviation values. Non-normally distributed data were reported as median and minimum-maximum values. In the univariate analyses, the chi-square or Fisher's exact test was used to compare categorical variables, and Student's t-test or the Mann-Whitney U-test to compare independent samples between the groups. Multivariate (logistic regression) analyses was performed to determine statistically significant independent factors. Statistical significance was considered when the two-tailed $\mathrm{p}$ value was $<0.05$.

\section{Results}

Of the 147 patients evaluated, $77(52.4 \%)$ had right ureteral stones and $70(47.6 \%)$ had left ureteral stones. The mean patient age was $42.4 \pm 12.8$ years (Table 1 ). The median transverse stone size was $7.5 \mathrm{~mm}$ (min 2.8 - $\max 15)$ and the median UWT was $4.2 \mathrm{~mm}(1$ - 8.7). The median stone density was $822 \mathrm{HU}$ (275 $1628)$, and the median stone volume was $277.4 \mathrm{~mm}^{3}(36-2134.8)$. The mean SSD was $124.8 \pm 23.6 \mathrm{~mm}$. Based on the data collected over a three-month follow-up period after SWL, $136(92.5 \%)$ of the patients were identified as stone-free while treatment failure was seen in $11(7.5 \%)$. In the presence of multiple stones, the stone-free rate was $50 \%$ (Table 2).

When stone-related parameters were analyzed statistically, UWT $(\mathrm{p}<0.001)$, presence of multiple stones $(\mathrm{p}<0.001)$, and increased diameter of the ureter in the proximal of the stone $(\mathrm{p}=0.050)$ were found to increase the treatment failure rate. Transverse stone size $(\mathrm{p}=0.883)$, stone length $(\mathrm{p}=0.365)$, stone volume $(\mathrm{p}=0.594), \mathrm{HU}(\mathrm{p}=0.819)$, side of the stone $(\mathrm{p}=0.160)$, and SSD $(\mathrm{p}=0.803)$ did not affect stone-free status (Table 2). In the receiver operating characteristic (ROC) curve analysis, the optimal threshold value for UWT and the diameter of the ureter in the proximal of the stone were determined as $5.25 \mathrm{~mm}$ and $11.95 \mathrm{~mm}$, respectively. The treatment was successful in all 124 patients $(100 \%)$ with a UWT of $<5.25 \mathrm{~mm}$. Among the patients who had a UWT of [?] $5.25 \mathrm{~mm}$, the treatment was successful in $12(52.1 \%)$ and failed in $11(47.9 \%$ ). The sensitivity of this threshold (UWT $<5.25 \mathrm{~mm}$ ) for SWL treatment success was $100 \%$, specificity was $91.2 \%$, positive predictive value was $47.8 \%$, and negative predictive value was $100 \%$.

When the patient-related factors were analyzed, although treatment failure increased in patients with comorbidities according to the univariate analysis $(\mathrm{p}=0.030)$, no relationship was found in the multivariate analysis $(\mathrm{p}=0.117)$. Age $(\mathrm{p}=0.083)$, gender $(\mathrm{p}=0.514)$, and history of operation $(\mathrm{p}=0.579)$ (Table 1$)$ did not affect the failure rate.

When the treatment modalities were examined, the median number of sessions was $2(1-7)$, the median number of shockwaves per session was $3000(300-3800)$ and the mean amount of energy applied per session was $75.7+-22.7$ joules. Treatment success increased as the number of sessions decreased $(\mathrm{p}=$ $0.001)$. However, no relation was found in the multivariate analysis $(\mathrm{p}=0.535)$. No statistically significant correlation was found between the failure rate and the number of median shockwaves $(\mathrm{p}=0.094)$ or the mean shockwave power applied $(\mathrm{p}=0.054)$ (Table 2$)$. Treatment success decreased in those who had undergone ancillary procedures $(\mathrm{p}=0.048)$ before $\mathrm{SWL}$, but no significant relationship was found in the multivariate analysis $(\mathrm{p}=0.989)$. The multivariate analysis revealed UWT $(\mathrm{p}=0.002)$ and multiple stone presence $(\mathrm{p}$ 
$=0.027)$ as independent predictive factors of stone-free status (Table 3).

\section{Discussion}

In the literature, the success rate of SWL treatment performed on proximal ureteral stones ranges from $48 \%$ to $96 \%$. [7,9,10] In a study conducted by Besien et al, it was stated that the success of SWL was affected by the experience and skill of the urologist. [11] In our study, the stone-free rate after SWL treatment was $92.5 \%$, which is and close to the upper limit given in the literature. We consider that in our study, stone targeting was standardized as it was performed by a single urologist with 30 years of SWL experience.

It is stated that the increase in the UWT in the SWL treatment is one of the factors affecting success. In a study conducted by Sarica et al., SWL treatment was performed in 111 patients who had impacted proximal ureteral stones, and the success rate was found to be $78.4 \%$ and the failure rate as $21.6 \%$. The median transverse stone size was reported as $8.9 \mathrm{~mm}$, and the optimal threshold value for UWT was calculated as $3.55 \mathrm{~mm}$, at which this parameter had $91.7 \%$ sensitivity and $77 \%$ specificity. It was concluded that UWT $>3.55 \mathrm{~mm}$ was an independent parameter affecting treatment failure.[6] In our study, the stone-free rate $(92.5 \%)$ was higher, which may be correlated with the lower mean transverse stone size in our study $(7.5$ $\mathrm{mm}$ vs $8.9 \mathrm{~mm})$. The UWT threshold value of our study $(5.25 \mathrm{~mm})$ was also higher than reported by Sarıca et al. $(3.55 \mathrm{~mm})$. In our study, the mean UWT was $4.2 \mathrm{~mm}$, and the selected cross-sectional range was 1.25 $\mathrm{mm}$ (a very thin cross-section range). However, Sarica et al. determined the mean UWT as $3.28 \mathrm{~mm}$ and did not specify the cross-sectional range. These factors may have led to the difference in the threshold values obtained. In a study by Yoshida et al., it was stated that the increase in UWT also decreased the success of URS.[12]

Extracorporeal shock wave lithotripsy treatment is minimally invasive and can be performed without anesthesia, but it is not as effective as the more invasive URS in the presence of a higher number of stones. Eden et al. found that in distal ureteral stones, the presence of multiple stones increased SWL treatment failure. The authors stated that the stone-free rate of the patients with single stones was $88 \%$, which decreased to $50 \%$ in those with multiple stones. [13] Similarly, in our study, the stone-free rate decreased by $50 \%$ in the patients with multiple stones, and the presence of multiple ureteral stones located above the iliac crest level further increased the SWL treatment failure rate. Yamashita et al. also stated that the presence of multiple stones was a parameter that increased URS failure.[14]

In a recent study by Guler et al., the diameter of the proximal ureter was found to be an independent parameter affecting the treatment success of proximal ureteral stones with SWL. [15] In our study, the diameter of the ureter in the proximal of the stone was found to increase treatment failure in the univariate analysis, but a similar relationship was not observed in the multivariate analysis. In parallel with the study of Guler et al., the hydronephrosis degree increased failure according to the univariate analysis, but no relation was found in the multivariate analysis.

It is considered that systemic diseases may affect inflammatory reaction caused by the stone on the ureteral mucosa. Hubert et al. found that patients with comorbidities had decreased SWL success. The treatment being successful was 2.4 times more likely in patients with one comorbidity compared to those without any comorbidity. [16] Dalibor et al. stated that there was no relationship between SWL success and comorbidities. [17] In our study, the univariate analysis revealed that among the ureteral stones above the iliac crest, the failure rate increased in the presence of comorbidities while no such association was detected in the multivariate analysis.

In a previous multi-center study conducted in our clinic, we created a nomogram for patients who underwent SWL in the pediatric group and found that a history of stone surgery on the same side affected the success of treatment. [18] However, when we conducted the current study with adult patients, we observed no relationship between treatment failure and having a history of previous stone surgery or ureteral stones above the iliac crest level.

In some patients, placing a ureteral double J catheter before SWL may be considered to improve treatment 
success and associated complications. Ghonelm et al. stated that there was no significant relationship between urethral stent placement and treatment success in impacted proximal ureteral stones. [19] As in our study, the univariate analysis undertaken by Yamashita et al. showed that patients undergoing urinary drainage had increased treatment failure, but no relation was found in the multivariate analysis. [7]

$\mathrm{Ng}$ et al. stated that SSD was a predictor of the success of SWL treatment, but they did not specify the mean SDD of the patients.[20] However, Mains et al. reported the mean SSD as $13 \mathrm{~cm}$ and noted that it did not affect SWL success. [21] We determined a similar mean SSD value $(12.5 \mathrm{~cm})$ in our study. Furthermore, similar to Mains et al., we did not find a relationship between SSD and SWL success. In many studies, it has been suggested that the size of the ureteral stone affects the success of SWL. [22,23] However, in our study, no significant relationship was found between stone size and treatment success. Contrary to what is stated in the EAU guidelines [1], no relationship was found in SWL success and stone-free status according to the stone density (HU) of patients in both the recent study of Yamashita et al. [7] and our study.

The limitation of our study was its retrospective nature. Since the definition of impacted stones is subjective, and there is no consensus among the clinicians in the literature, we did not classify the stones as impacted or non-impacted in this study. With the growing SWL experience globally and according to our data, the predictive factors used to increase SWL success may change in the coming years.

\section{Conclusion}

We found that in the treatment of ureteral stones above the iliac crest level with SWL, UWT was the most important independent variable that increased treatment failure. Although not as strong as UWT, the presence of multiple stones was another independent factor that increased failure. The use of SWL technology and growing experience concerning the mechanical hardware of the machine can further improve treatment results and lead to the most minimally invasive treatment option becoming more popular.

\section{References}

[1] Turk C, Neisius A, Petrik A, Seitz C, Skolarikos A, Thomas K et al. EAU Guidelines on Urolithiasis. European Association of Urology. https://uroweb.org/guideline/urolithiasis/ Edn. Presented at the EAU Annual Congress Amsterdam 2020. EAU Guidelines Office, Arnhem, The Netherlands. ISBN 978-94-9267107-3.

[2] Preminger G. M. et al. 2007 Guideline for the Management of Ureteral Calculi. J. Urol. 2007; vol. 178, no. 6, pp. 2418-2434. DOI: 10.1016/j.eururo.2007.09.039

[3] Acón L., Daniel J., Villa T., Baenas C., Jurado O., and Tormo B. Analysis of the Efficacy and Safety of Increasing the Energy Dose Applied per Session Through Increasing the Number of Shock Waves in Extracorporeal Lithotripsy : a Prospective and Comparative Study. 2017; pp. 1-22. DOI:10.1089/end.2017.0261

[4] Mugiya S., Ito T., Maruyama S., Hadano S., and Nagae H. Endoscopic Features of Impacted Ureteral Stones. J. Urol. 2004; vol. 171, no. 1, pp. 89-91. DOI: 10.1097/01.ju.0000100960.08768.81

[5] Deliveliotis C., Chrisofos M., Albanis S., Serafetinides E., Varkarakis J., and Protogerou V. Management and Follow-up of Impacted Ureteral Stones. Urol. Int. 2003; vol. 70, no. 4, pp. 269-272. DOI: $10.1159 / 000070133$

[6] Sarica K. et al. Ureteral Wall Thickness at the Impacted Ureteral Stone Site: a Critical Predictor for Success Rates After SWLUrolithiasis . 2014;vol. 43, no. 1, pp. 83-88. DOI: 10.1007/s00240-014-0724-6

[7] Yamashita S., Kohjimoto Y., Iguchi T., Nishizawa S., Kikkawa K., and Hara I. Ureteral Wall Volume at Ureteral Stone Site is a Critical Predictor for Shock Wave Lithotripsy Outcomes : Comparison with Ureteral Wall Thickness and Area. Urolithiasis . 2019; no. 0123456789. DOI: 10.1007/s00240-019-01154-w

[8] Wiesenthal J. D., Ghiculete D., Honey J. D., and Pace K. T. Evaluating the Importance of Mean Stone Density and Skin-to-Stone Distance in Predicting Successful Shock Wave Lithotripsy of Renal and Ureteric Calculi. 2010; pp. 307-313. DOI: 10.1007/s00240-010-0295-0 
[9] Liong N. L., Clayman R. V., Gittes R. F, Lingeman J. E., Huffman J. L, and Lyon E. Treatment Options for Proximal Ureteral URolithiasis : Review and Recommendations. 1989; vol. 141, pp. 504-509. DOI: 10.1016/s0022-5347(17)40874-3

[10] Goren et al. Endourology and Stones Time to Stone Clearance for Ureteral Stones Treated with Ekstracorporeal Shock Wave Lithotripsy. URL . 2011; vol. 78, no. 1, pp. 26-30. DOI: 10.1016/j.urology.2010.10.060

[11] Besien J. V., Uvin P., Hermie I., Tailly T., and Merckx L. Ultrasonography Is Not Inferior to Fluoroscopy to Guide Extracorporeal Shock Waves during Treatment of Renal and Upper Ureteric Calculi : A Randomized Prospective Study. 2017; vol. 2017. DOI: 10.1155/2017/7802672

[12] Yoshida, T., Inoue, T., Omura, N., Okada, S., Hamamoto, S., Kinoshita, H., \& Matsuda, T. Ureteral wall thickness as a preoperative indicator of impacted stones in patients with ureteral stones undergoing ureteroscopic lithotripsy. Urology. 2017; 106, 45-49. https://doi.org/10.1016/j.urology.2017.04.047

[13] Eden C. G., Mark I. R., Gupta R. R., Eastman J., Shrotri N. C. \& Tiptaft R. C. Intracorporeal or extracorporeal lithotripsy for distal ureteral calculi? Effect of stone size and multiplicity on success rates. Journal of endourology. 1998; 12(4), 307-312. DOI: 10.1089/end.1998.12.307

[14] Yamashita S., Iwahashi Y., Deguchi R., Kikkawa K., Kohjimoto Y., \& Hara I. Three-dimensional mean stone density on non-contrast computed tomography can predict ureteroscopic lithotripsy outcome in ureteral stone cases. Urolithiasis. 2020; 1-6. DOI: 10.1007/s00240-020-01178-7

[15] Guler, Y., Erbin, A., Kafkasli, A., \& Ozmerdiven, G. Factors affecting success in the treatment of proximal ureteral stones larger than $1 \mathrm{~cm}$ with extracorporeal shockwave lithotripsy in adult patients. Urolithiasis. 2020; 1-6. DOI: 10.1007/s00240-020-01186-7

[16] Hubert KC S. M., Singh M, Zhou EH, Santos G. Charlson comorbidity index and success of extracorporeal shock wave lithotripsy. Can J Urol. 2009; 16(4), 4733-4735.

[17] Simunovic D., Sudarevic B., Galic J. Extracorporeal Shockwave Lithotripsy in Elderly : Impact of Age and Comorbidity on Stone-Free Rate and Complications. 2010; vol. 24, no. 11, pp. 1831-1837. DOI: 10.1089/end.2009.0329

[18] Onal B., Tansu N., Demirkesen O., Yalcin V., and Huang L. Nomogram and scoring system for predicting stone-free status after extracorporeal shock wave lithotripsy in children with urolithiasis. 2012pp. 3; 44-352. DOI: $10.1111 / \mathrm{j} .1464-410 \mathrm{X} .2012 .11281 . \mathrm{x}$

[19] Ghoneim I. A., El-Ghoneimy M. N., El-Naggar A. E., Hammoud K. M., El-Gammal M. Y. \& Morsi A. A. Extracorporeal shock wave lithotripsy in impacted upper ureteral stones: a prospective randomized comparison between stented and non-stented techniques. Urology. 2010; 75(1), 45-50. DOI: $10.1016 /$ j.urology.2009.06.071

[20] Ng C., Siu D. Y., Wong A., Goggins W., Chan E. S. and Wong K. Development of a Scoring System From Noncontrast Computerized Tomography Measurements to Improve the Selection of Upper Ureteral Stone for Extracorporeal Shock Wave Lithotripsy. JURO . 2009; vol. 181, no. 3, pp. 1151-1157, DOI: 10.1016/j.juro.2008.10.161

[21] Mains E. A., Blackmur J. P., Sharma A. D., Gietzmann W. K., El-Mokadem I., Stephenson C. \& Cutress M. L. Shockwave Lithotripsy Is an Efficacious Treatment Modality for Obese Patients with Upper Ureteral Calculi: Logistic Regression and Matched-Pair Analyses from a Dedicated Center Comparing Treatment Outcomes by Skin-to-Stone Distance. Journal of Endourology. 2020; 34(4), 487-494. DOI: 10.1089/end.2019.0717

[22] Sugino Y., Kato T., Furuya S., Sasaki T., Arima K., and Sugimura Y. The Usefulness of the Maximum Hounsfield Units (HU) in Predicting the Shockwave Lithotripsy Outcome for Ureteral Stones and the Proposal of Novel Indicators Using the Maximum HU. Urolithiasis . 2020; vol. 0, no. 0, p. 0. DOI: 10.1007/s00240-019-01123-3 
[23] Wolf J. S. Jr. Treatment Selection and Outcomes : Ureteral Calculi. 2007; vol. 34, pp. 421-430. DOI: 10.1016/j.ucl.2007.04.010

Table 1 . Comparison of the outcomes in terms of demographic characteristics

\begin{tabular}{|c|c|c|c|c|}
\hline & & & & $\mathbf{p}$ \\
\hline & Overall (147) & $\begin{array}{l}\text { Stone-Free } \\
(136)\end{array}$ & Failure (11) & \\
\hline Age (Year) & $42.46 \pm 12.83$ & $41.9 \pm 12.8$ & $48.9 \pm 11.8$ & $0.083^{+}$ \\
\hline $\begin{array}{l}\text { Gender n, (\%) Male } \\
\text { Female }\end{array}$ & $\begin{array}{l}108(73.5 \%) 39 \\
(26.5 \%)\end{array}$ & $\begin{array}{l}99(91.6 \%) 37 \\
(94.8 \%)\end{array}$ & $9(8.4 \%) 2(5.2 \%)$ & $0.514^{++}$ \\
\hline $\begin{array}{l}\text { History of surgery } \\
n,(\%) \text { Yes No }\end{array}$ & $\begin{array}{l}8(5.4 \%) 139 \\
(94.6 \%)\end{array}$ & $\begin{array}{l}7(87.5 \%) 129 \\
(92.8 \%)\end{array}$ & $1(12.5 \%) 10(7.2 \%)$ & $0.579^{++}$ \\
\hline $\begin{array}{l}\text { Comorbidity n, (\%) } \\
\text { Yes No }\end{array}$ & $\begin{array}{l}18(12.2 \%) 129 \\
(87.8)\end{array}$ & $\begin{array}{l}14(77.7 \%) 122 \\
(94.5 \%)\end{array}$ & $\begin{array}{l}4(22.3 \%) 7 \\
(5.5 \%)\end{array}$ & $0.030^{++}$ \\
\hline $\begin{array}{l}+\mathrm{T} \text { test in } \\
\text { independent } \\
\text { groups, }{ }^{++}\end{array}$ & $\begin{array}{l}+\mathrm{T} \text { test in } \\
\text { independent } \\
\text { groups, }{ }^{++}\end{array}$ & $\begin{array}{l}+\mathrm{T} \text { test in } \\
\text { independent } \\
\text { groups, }{ }^{++}\end{array}$ & $\begin{array}{l}+\mathrm{T} \text { test in } \\
\text { independent } \\
\text { groups, }++\end{array}$ & $\begin{array}{l}+\mathrm{T} \text { test in } \\
\text { independent } \\
\text { groups, }{ }^{++}\end{array}$ \\
\hline Fisher's Exact & Fisher's Exact & Fisher's Exact & Fisher's Exact & Fisher's Exact \\
\hline Test & Test & Test & Test & Test \\
\hline
\end{tabular}

Table2. Comparison of the outcomes in terms of stone and treatment characteristics

p

\begin{tabular}{|c|c|c|c|c|}
\hline & & & & $\mathbf{p}$ \\
\hline & Overall (147) & $\begin{array}{l}\text { Stone-Free } \\
(136)\end{array}$ & Failure (11) & \\
\hline $\begin{array}{l}\text { Side of stone n, (\%) } \\
\text { Left Right }\end{array}$ & $70(47.6) 77(52.4)$ & $67(95.7) 69(89.6)$ & $3(4.3) 8(10.4)$ & $0.160^{++}$ \\
\hline $\begin{array}{l}\text { HU median, } \\
\text { (range) }\end{array}$ & $822(275-1628)$ & $826(275-1628)$ & $770(345-1548)$ & $0.819 \mathbb{I}$ \\
\hline $\begin{array}{l}\mathrm{HU} n,(\%)<1000 \\
{[?] 1000}\end{array}$ & $106(72.1) 41(27.9)$ & $98(92.5) 38(92.7)$ & $8(7.5) 3(7.3)$ & $1 \S$ \\
\hline $\begin{array}{l}\text { Stone length } \\
\text { (mm) median, } \\
\text { (range) }\end{array}$ & $11(3-24)$ & $11(3-24)$ & $12(6.6-19.5)$ & $0.365 \mathbb{I}$ \\
\hline $\begin{array}{l}\text { Stone volume } \\
\left(\mathrm{mm}^{3}\right) \text { median, } \\
\text { (range) }\end{array}$ & $277(36-2134)$ & $277(36-2134)$ & $\begin{array}{l}384.2(87.5- \\
895.1)\end{array}$ & $0.594 \mathbb{I}$ \\
\hline $\begin{array}{l}\text { Transverse stone } \\
\text { size (mm) } \\
\text { median, (range) }\end{array}$ & $7.5(2.8-15.3)$ & $7.4(2.8-15.3)$ & $8(5.1-10)$ & $0.883^{\mathbb{I}}$ \\
\hline $\begin{array}{l}\text { Diameter of the } \\
\text { ureter proximal of } \\
\text { the stone (mm) } \\
\text { median, (range) }\end{array}$ & $11(6-28.7)$ & $11.5(6-28.7)$ & $13(9.7-18.8)$ & $0.050 \mathbb{I}$ \\
\hline HN (Grade) n, (\%) & $10(6.8) 105$ (71.4) & $10(100) 99(94.2)$ & $06(5.8) 5(17.3) 0$ & $0.075^{\S}$ \\
\hline 0123 & $29(19.7) 3(2)$ & $24(82.7) 3(100)$ & & \\
\hline $\begin{array}{l}\text { Number of Stone n, } \\
\text { (\%) Single Multiple }\end{array}$ & $141(95.9) 6(4.1)$ & $133(94.3) 3(50)$ & $8(5.7) 3(50)$ & $0.006 \S$ \\
\hline
\end{tabular}




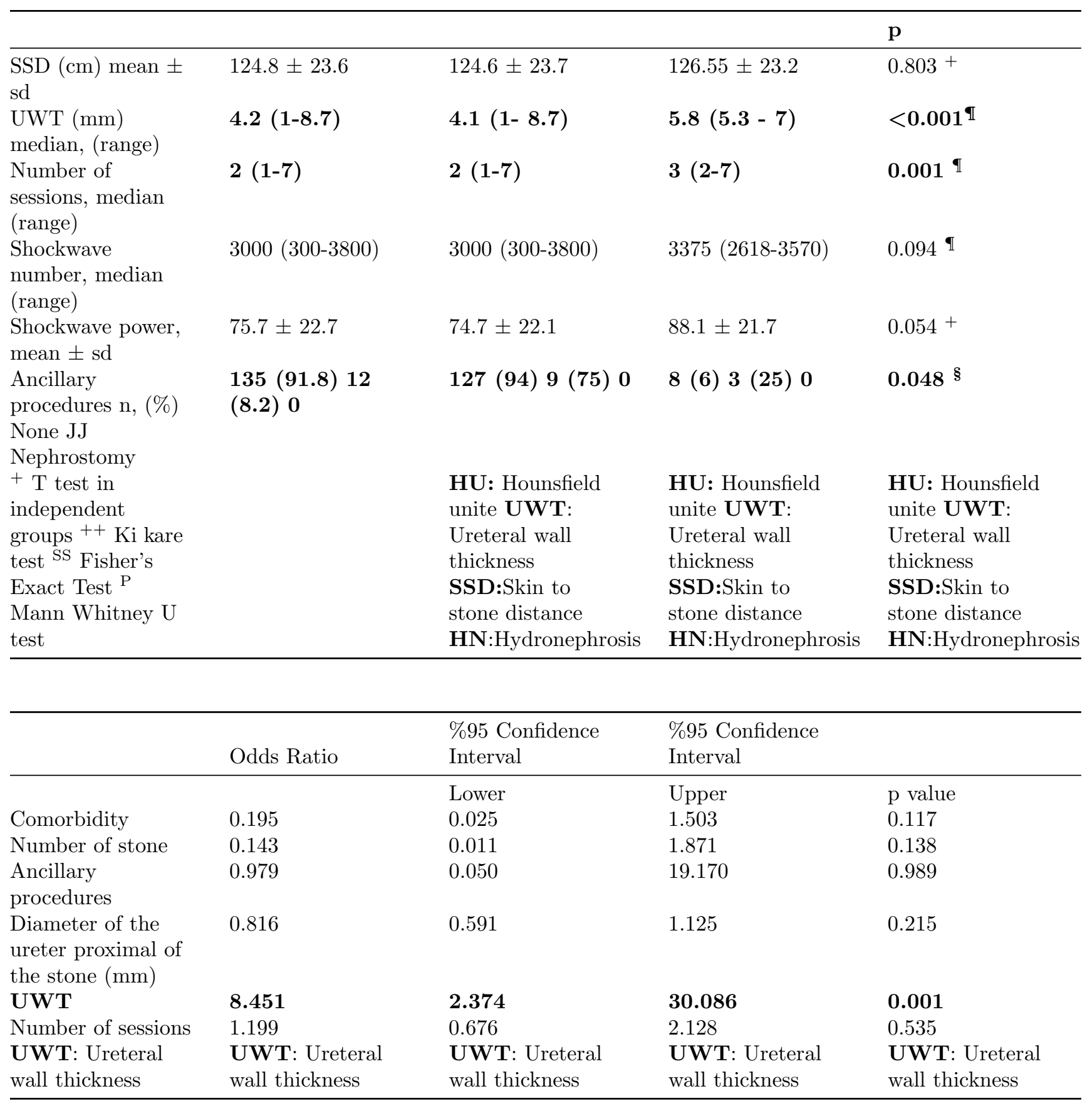

Table 3. Multivariate Analysis of Stone-Free and Parameters in SWL

\section{Figure Legends:}

Figure 1: Evaluating the UWT in the axial plane measurement. The largest UWT was obtained from NCCT at the stone site.

Figure 2: Evaluating the UWT in the coronal plane measurement.

Figure 3: Evaluating the UWT in the sagittal plane measurement. 


\section{Hosted file}

Figures.pdf available at https://authorea.com/users/380575/articles/496486-ureteral-wallthickness-is-an-independent-parameter-affecting-the-success-of-extracorporeal-shockwave-lithotripsy-treatment-in-ureteral-stones-above-the-iliac-crest 